\title{
Multiplex Value Cocreation in Unique Service Exchanges
}

\author{
Kamran Razmdoost \\ ESCP Europe Business School, 527 Finchley Road, London, UK, NW3 7BG, krazmdoost@escpeurope.eu, \\ $+442074438861$

\section{Leila Alinaghian} \\ Cranfield University, Cranfield School of Management, Cramfield Road, Cranfield, Bedford, UK, MK43 0AL, \\ leila.alinaghian@cranfield.ac.uk,+441234750111 x2883 \\ Hedley J. Smyth \\ University College London, The Bartlett School of Construction and Project Management, 1-19 Torrington Place, \\ London, UK, WC1E 6BT, h.smyth@ucl.ac.uk, +442076795908
}

\begin{abstract}
:
While the temporal nature of value cocreation (i.e., the interdependencies between/among past, present, and future value cocreation) is acknowledged in the literature, the processes and mechanisms through which these interdependencies are deliberately managed (i.e., multiplex value cocreation) are not examined. Our study aims to unravel the "black box" of multiplex value cocreation by investigating the processes and mechanisms through which actors manage the temporal nature of value cocreation in unique service exchanges. The research design is a multiple case study comprising four firms engaged in the definition, design, and delivery of mega-infrastructure projects. Our results showed that multiplex value cocreation involves two core processes of institutional work and resource reconfiguration that are reciprocally interrelated, driven by actor motives and conflicts and facilitated by interaction mechanisms. We further propose that emerged institutions and existing previous similar service exchanges may eliminate the need for multiplex value cocreation in routine service exchanges.
\end{abstract}

Keywords: value co-creation, project, service ecosystem, service dominant logic, temporal, unique service 


\section{Introduction}

Value and value creation play a crucial role in determining the well-being of any social entity

(e.g., individuals and businesses). Extensive conceptual and empirical efforts have been allocated to deconstructing and theorizing the way in which value is created in service exchanges (Gummerus, 2013). In particular, the proposed conceptualizations have evolved from the idea of value being created by a single provider (Porter, 1985) or a chain or a network of providers (Christopher, 2005) to the notion of value being cocreated by the customer and provider (Vargo \& Lusch, 2004; 2008) or by multiple actors, including the beneficiary (Vargo \& Lusch, 2016). The cocreation paradigm specifically places significant emphasis on the contributions of (all) different actors involved in the creation of value (Vargo \& Lusch, 2008; 2016). In particular, the latest conceptualization of value cocreation associates the phenomenon with service ecosystems as a "relatively self-contained self-adjusting system of resource-integrating actors connected by shared institutional logics and mutual value creation through service exchange" (Vargo \& Lusch, 2016, p. 10).

Existing empirical studies investigating value cocreation have identified a set of resource integration processes and interaction mechanisms that contribute to the well-being of service ecosystem actors. For instance, in a healthcare context, resource integration processes such as engagement in diet control and physical exercise are shown to enhance the health conditions of customers (McColl-Kennedy, Hogan, Witell, \& Snyder, 2017). Similarly, Pera, Occhiocupo, and Clarke (2016) investigated actors' motives and joint decision-making (as forms of resource integration processes) as well as online and offline communication encounters (as forms of interaction mechanisms) as the core enablers of the Expo 2015 Universal success. 
Actors' engagement in these resource-integrating processes and interaction mechanisms, whether intentional, unintentional, conscious or unconscious, are influenced by the outcomes (i.e., resources, institutions, and experiences) created in the past and may impact, and thus be influenced by, the outcomes created in an imaginary future (Chandler \& Lusch, 2015; Chandler \& Vargo, 2011; Storbacka, Brodie, Böhmann, Maglio, \& Nenonen, 2016). For instance, two drivers with the same make-and-model car on the same road may drive differently due to their past driving experiences and training. We refer to the interdependencies between past, present, and future value cocreation processes and mechanisms as the temporal nature of value cocreation. The notion of temporality in the context of value cocreation is also introduced and conceptualized in the actor engagement literature (e.g., Chandler \& Lusch, 2015; Storbacka et al., 2016), where scholars introduced temporal connection as an actor engagement property, elucidating that actors' present connections are impacted by past experiences and are oriented towards the future.

Most often the temporality of value cocreation is managed by resources and institutions that emerge over time as the constituents of value cocreation (e.g., competencies, social norms and symbols; Akaka, Vargo, \& Schau, 2015) (see curved arrows in Figure 1). In the aforementioned example, the drivers' previous driving experiences are manifested through resources such as their knowledge of the road or driving competency in their present driving experience. However, there are also instances where service ecosystem actors are required to deliberately put in place processes and mechanisms to manage the temporality of value cocreation. In the driving example, driver-licensing agencies set regulations and processes to ensure that the drivers are familiar with driving regulations (i.e., they have had formal training in the past) before allowing them to drive (in the present). At the same time, to be eligible to drive, 
the drivers engage in the process of obtaining a driver's license by learning the traffic regulations and driving practices and taking the driving test. We label the processes and mechanisms that actors deliberately put in place to manage the temporal nature of value cocreation as multiplex value cocreation. In particular, multiplex value cocreation appears where the temporal nature of value cocreation is a potential source of conflict among actors (e.g., failing to learn the rules and regulations of driving [in the past] would cause unsafe conditions for others [in the present]). While playing an integral role in value cocreation, multiplex value cocreation has largely been overlooked in the literature. Our study seeks to explain the nuances of the recent thinking with regard to the temporal nature of value cocreation by teasing out and distinguishing the processes and mechanisms through which actors manage the interrelationship between past, present, and future value cocreation (i.e., multiplex value cocreation, see dotted arrows in Figure 1) from those of core value cocreation activities (see horizontal solid arrows in Figure 1).

\section{INSERT FIGURE 1 ABOUT HERE}

Multiplex value cocreation is particularly evident in a unique service exchange (as opposed to a routine service exchange). Routine service exchanges are predominantly associated with the concept of practice (i.e., a routinized way in which actors engage with life activities; Warde, 2005), whereby actors repeatedly engage with the exchange to achieve their everyday (repeated) goals. In contrast, there are one-off service exchanges to address actors' unique goals. These unique service exchanges are mainly referred to as projects (e.g., Watson \& Shove, 2008; Razmdoost \& Mills, 2016). While projects may consist of practices (e.g., project time and cost management practices; Papke-Shields, Beise, \& Quan, 2010) and practices often encompass projects (e.g., to enable the practice of children playing every day, one may engage in an attic 
redecoration project to create a play space; Watson \& Shove, 2008), the two differ in that the overall exchange is set to address a unique goal in the case of a project but a routine goal in the case of a practice. Routine and unique service exchanges are specifically different in the way they manage conflicts arising from the temporal nature of value cocreation. In routinized service exchanges, the temporal conflicts are resolved through the replication of practices and institutions, whereby the service ecosystem, while dynamically changing, stabilizes over time (Chandler \& Vargo, 2011). Hence, in these settings, actors' efforts in resolving temporal conflicts of value cocreation may not be explicitly observable. For instance, it may be difficult to uncover the processes and mechanisms that led to the establishment of driver-licensing agencies in the example above. However, in unique service exchanges, potential temporal conflicts have to be managed in the one-off service exchange. For instance, a household renovating a home would need to develop and sign a contract with the potential builder to ensure the integration of promised resources in future. Unique service exchanges therefore would provide an appropriate setting that permits exploration of multiplex value cocreation that may not be (completely) apparent in a routine service exchange. Thus, our study aims to unravel the black box of multiplex value cocreation by investigating the processes and mechanisms through which actors manage the temporal nature of value cocreation in unique service exchanges.

\section{Theoretical background}

\subsection{Value cocreation}

Value cocreation includes actors involved in resource integration (i.e., processes that result in summative or emergent relations between/among resources; Peters, 2016) and service exchange (i.e., the exchange of benefits that arise from resource integration; adapted from Vargo \& Lusch, 2004) occurring through interaction mechanisms that are enabled and constrained by actor- 
generated institutions (e.g., norms, collaboration means, and symbols) and institutional arrangements that are interdependent assemblages of institutions (e.g., legal system and policy arrangement) (Akaka, Vargo, \& Lusch., 2013; Vargo \& Lusch, 2016). Although certain scholars have argued that direct interactions (e.g., collaborative, dialogical joint processes; Grönroos \& Voima, 2013) are the core basis of value cocreation (Grönroos, 2011), value cocreation also takes place through multiple actors integrating resources in the service ecosystem regardless of whether or not they interact directly (Vargo \& Lusch, 2016). Indeed, interaction, as an inherent component of value cocreation, is beyond direct contacts, service encounters, or joint processes, and includes any mechanism (e.g., dialog, resource transfer, and learning; Gummesson \& Mele, 2010) that enables actors to participate in value cocreation (i.e., being part of improving the wellbeing of other actors).

The existing literature has investigated the microfoundations of value cocreation by identifying the processes underpinning resource integration and the enabling mechanisms of actors' interactions. Firstly, scholars have identified a number of resource integration processes by focusing on a particular actor or a specific objective. For example, by concentrating on customers' actions, McColl-Kennedy, Vargo, Dagger, Sweeney, and van Kasteren (2012) investigated resource integration with respect to a set of processes, such as changing the ways of doing things, cooperating, and combining complementary therapies. Similarly, focusing on problem-solving as the core objective of value cocreation, Aarikka-Stenroos and Jaakkola (2012) determined resource integration as a problem-solving process wherein the provider's and customer's resources are integrated to diagnose the problem, organize the processes to solve the problem, find the solution, solve the problem, and manage the conflicts surrounding value. While more recently there have been attempts to establish a comprehensive set of processes that 
underlie resource integration (e.g., Tommasetti, Troisi, \& Vesci, 2017), the integration processes through which the temporal nature of value cocreation is addressed have largely remained unexplored.

Secondly, the interactions between/among social actors or between social actors and resources as the core enablers of value cocreation (McColl-Kennedy et al., 2017; Storbacka et al., 2016) are captured through a set of mechanisms (e.g., dialog and resource transfer; Gummesson \& Mele, 2010). For instance, because actors need to know the existing resources within the service ecosystem and reciprocally make other actors aware of theirs (Ballantyne, Frow, Varey, \& Payne, 2011), communication encounters are identified as a crucial interaction mechanism in value cocreation (Pera et al., 2016). Indeed, any engagement platform, such as virtual or real marketplaces and social networks, is an interaction mechanism supporting value cocreation (Breidbach \& Brodie, 2017). While the literature has begun to acknowledge the interaction mechanisms that support value cocreation, it falls short of examining those interaction mechanisms that actors set to manage the temporal nature of value cocreation.

\subsection{Temporal nature of value cocreation}

The interdependencies between actors' actions in the past, present, and future (i.e., the temporal nature of value cocreation) have been acknowledged in the literature (e.g., Chandler \& Vargo, 2011; Chandler \& Lusch, 2015). Specifically, in addition to the dynamic and evolving nature of value cocreation over time (as suggested by institutional logic; Vargo \& Lusch, 2016), it is argued that value cocreation (at each point in time) is affected by actors' actions in the past and is oriented towards the future. For instance, as humans have the ability to deal with time and integrate the past and present with the future (Chandler \& Vargo, 2011), past service exchanges can impact actors' present engagement (i.e., temporal connection; Chandler \& Lusch, 2015). 
Despite the recognition of value cocreation temporality, little is understood about how the interdependencies between past, present and future actions are managed. Current literature on value outcomes, however, has investigated the interdependencies between/among experiences (as value outcomes) at different points in time (i.e., the temporal nature of value). This is particularly recognized by Helkkula, Kelleher, and Pihlstrom (2012) in terms of the notion of value-in-experience (i.e., actors' lived experiences of service beyond the present context of use, including past and future experiences). From this viewpoint, value is both lived and imagined, and can be created based on past, present, and/or future experiences. This idea is further developed by Chandler and Lusch (2015), who introduced the concept of temporal connection as an actor engagement property representing "actors' present-day connections [or relations] that have emerged from past experiences and are oriented towards future experiences" (p. 10). In a similar vein, Truong, Simmons, and Palmer (2012) empirically illustrated that actors' social relations are facilitated by their reciprocal exchanges of value propositions over time.

Value cocreation processes and mechanisms are also influenced by actors' previous actions and are oriented towards future value cocreation activities. In many cases, the temporality of value cocreation is managed through resources and institutions that emerge in service ecosystems to enable actors' interaction and resource integration. For instance, previous experiences of the wait staff at a restaurant makes them competent (i.e., emerged resources) in serving customers. Furthermore, previous restaurant experiences of customers create social norms and symbols, such as dining style, languages, etc. (i.e., emerged institutions), that then enables their engagement with restaurant services (Akaka et al., 2015). This is consistent with the notion of historical dependency of service ecosystems (Meynhardt, Chandler, \& Strathoff, 2016) and interdependency of emerged resources (Peters, 2016). However, in other cases, particularly 
where the interdependencies of actors' actions over time can lead to conflicts, service ecosystem actors deliberately create processes and mechanisms that will enable them to manage the temporal nature of value cocreation (i.e., multiplex value cocreation). For instance, actors need to develop certain mechanisms (i.e., a form of multiplex value cocreation) where there are differences of opinion on how a future activity must be performed, or conflicts may arise due to the potential changes in the resources that actors bring to the service exchange (Mele, 2011). Despite their presumably significant role in addressing the temporal nature of value cocreation, multiplex value cocreation has remained a "black box" in value cocreation research.

\subsection{Value cocreation in projects as unique service exchanges}

Multiplex value cocreation is particularly salient in projects where actors engage in a one-off service exchange with a unique goal and application of resources. Projects as "unique endeavour[s] — in the sense of a one-off — undertaken to accomplish a defined objective" (Morris, 2002, p. 83) represent a specific form of unique service. Uniqueness as the main characteristic of projects (Morris, 2002) creates uncertainty and transience (Turner \& Müller, 2003). In order to manage uncertainties, projects follow a generic lifecycle process, including conceptualization, feasibility, definition, execution, and close-out (Morris, 2013; Ward \& Chapman, 1995).

While the phenomenon of value cocreation has been assessed in the context of projects (e.g., Smyth, Lecoeuvre, \& Vaesken, 2018), these studies have largely looked into the integration of actors' resources with those of others through a collaborative, dialogical joint process (i.e., a direct interaction; Grönroos \& Voima, 2013; Grönroos \& Gummerus, 2014). For instance, contract co-development (Crespin-Mazet \& Ghauri, 2007), early contractor involvement (Liu, Fellows, \& Chan, 2014), customer involvement in defining development projects (Hsu, Hung, Chen, \& Huang, 2013), and multi-level distributed interactions (Razmdoost \& Mills, 2016) have 
been recognized as examples of the value cocreation process. Mele (2011) further explored the conflicts that may emerge within these direct interactions. In particular, she examined the means through which these conflicts are managed in projects and how the un-resolved conflicts may impede value cocreation. While projects as unique service exchanges would offer a useful setting for the examination of value cocreation temporality, value cocreation in projects has not been examined beyond direct interactions.

\section{Method}

Given the limited theory and empirical evidence related to multiplex value cocreation, our work adopts an exploratory approach. As natural settings that consider temporal aspects of a contemporary phenomenon, case studies are considered an appropriate method (Yin, 2013). Specifically, our research is inductive in nature and uses multiple case studies to uncover the processes and mechanisms through which actors manage the temporal nature of value cocreation. Although multiple case studies are potentially limited in generating rich contextual data and data-driven paradigm-shifting theory (Dyer \& Wilkins, 1991), the use of multiple cases has improved the robustness of the underpinning constructs of multiplex value cocreation derived through replication (Eisenhardt \& Graebner, 2007).

\subsection{Case selection}

The research design is a multiple case study comprising four firms engaged in at least one mega infrastructure project (employing the pragmatic definition of $>$ US $\$ 1$ billion) over the last five years of the study. A purposeful sampling approach (Patton, 2015) was used to select those cases that were particularly suitable for illuminating the value cocreation processes that cross time contexts to manage the underlying interdependencies. The case selection was primarily driven by 
two considerations. First, we chose our cases from those firms that predominantly engage in service exchanges through projects as a form of unique service exchange (i.e., project-based firms; Blindenbach-Driessen \& van den Ende, 2006). Second, we opted for firms from the infrastructure, building and construction industry, where, in contrast to many project-based industries, there is little opportunity for routinizing the service exchange. For example, while in recent years the information technology (IT) sector and the residential building construction businesses have both routinized their service delivery through practices like modularization, bundling, or the standardization of design, infrastructure projects are predominantly unique with respect to funding, design, construction, completion, delivery, and maintenance. Additionally, in order to provide a complete understanding of the multiplex value cocreation phenomenon, we tried to take into account the views of actors adopting different roles in the ecosystem - that is, one main infrastructure client (Case I), active in the transportation industry, was selected to represent the customer side of value cocreation. In addition, three major international construction contractors that had exchanges with the selected client were chosen to represent the provider side of value cocreation (Cases II-IV). The confidentiality agreement between the researchers and the participating firms stipulated that the names of the firms should remain anonymous throughout the process.

Each of the case companies undertakes large and complex projects with high levels of uncertainty and risk, because securing the provider for Case I and securing the contract for Cases II-IV occurred ahead of provision and these megaprojects often involve the creation of new processes, technologies, and business models. Each of the case companies are briefly introduced, as are their background details in the context of their logic of marketing across the featured projects. Data are predominantly collected and analyzed through the examination of a set of 
projects within each case company, as unique forms of service exchange that are embedded in a broader service ecosystem. We thus provide a brief summary of the types of projects studied along with the issues related to the temporal nature of value cocreation in Table 1.

\section{INSERT TABLE 1 ABOUT HERE}

\subsubsection{Case I}

The client, Case I, is a national public-sector provider run as a commercial organization. It receives central government funding, and income is generated from its infrastructure and service provision. The infrastructure is commissioned and owned by the client, while provision is through large, main contractors. The concession income is from rail operations concessions. This part of the business is not project-based and thus was excluded from our study. The client, in addition to commercial pressures, is also subject to changing economic policies and budget scrutiny by the central government finance ministry. This results in financial uncertainty, particularly for the project part of the business. The accountability tension between market and public factors has historically led to short-term outcomes being prioritized to satisfy budgetary outcomes on the supply side over service outcomes in use. A large infrastructure program for upgrades and renewal, as well as new infrastructure, was underway during the data collection period.

\subsubsection{Case II}

Case II is a large national main contractor with extensive overseas interests in mainstream infrastructure and engineering contracting. The firm has historically undertaken a considerable amount of work for the client represented in Case I. However, the proportion of work secured by Case II from this client has diminished recently and thus was not covered in our data collection. 
Case II is generally recognized as being highly transactional, whereby its main focus lies in project criteria, including time, cost, quality, and scope (as opposed to relational measures). However, its size and areas of specialist technical capabilities have kept it in a dominant position, particularly in transportation infrastructure markets. The infrastructure projects (both new and renewal work) the firm undertakes are highly varied and frequently complex, with high uncertainty levels that defy routinization below the strategic level of operations management for construction.

\subsubsection{Case III}

Case III is an international contractor that has expanded internationally through takeovers, especially in infrastructure markets. It also owns subsidiaries with specialist engineering capabilities in infrastructure and therefore has been involved in a range of related projects, including work for the Case I client as both a main contractor and specialist subcontractor. Case III is generally recognized as being collaborative, although its ability to manage interactions is uneven and the associated service experience during execution is apparent on the market as variable. It can become very transactional at an operational level. This feature affects its ability to secure work on a consistent basis in the market, keeping in mind that, in project markets, contractors sell first and provide subsequently and, therefore, the variability of service experience induces relational and contractual uncertainty from the client perspective.

\subsubsection{Case IV}

Case IV is an international main contractor with specialist engineering capabilities in infrastructure and, similar to Case III, has expanded internationally through takeovers in the building and infrastructure markets. Case IV has been involved in a number of infrastructure projects, including work for the Case I client. The company is known as being collaborative 
owing to both the national and organizational culture from which it hails. Its capacity to manage interactions is robust, particularly at a senior management level. Operationally, there are projects where transactional behavior can surface and, on occasions, become dominant. The service experience during execution is renowned on the market as reasonably sound and it has the ability to manage complex multi-organizational project teams. However, risk and financial management remain important considerations and can lead to short-term thinking at the expense of long-term outcomes for both the service experience during execution and the use of the project postcompletion.

\subsection{Data collection}

Semi-structured interviews were the major data collection method. Respondents were selected from middle management and executive-level managers because they had the most influence on interactions with other firms. Each interview was conducted face to face, lasting 55 to 90 minutes. The variety of positions of respondents helped to provide both individual- and businesslevel data on value cocreation processes. Interviews were carried out with personnel that held similar designations across the cases, enabling the authors to strengthen the external validity of the findings (Yin, 2013) (see Table 1).

Data collection began by conducting at least one initial discussion session with a principal informant at each case company. The principal informants were senior directors who had extensive experience, strategic vision, and a deep understanding of the project and program portfolios across functions. Specifically, during these sessions, the principal informants were asked to nominate key megaprojects that were both recent (i.e., over the last 5 to10 years) and strategic for the case company. Consequently, respondents were selected from senior managers and directors across multiple functions who had been involved in these projects. 
The respondents were requested to explicate the project from the inception of needs awareness to funding, design, and execution. In particular, in order to garner more insights into value cocreation processes, we asked the respondents to reflect on the specific interactive activities taking place with other actors (e.g., contractor, client, and government) throughout the project life cycle. For instance, we posed the following questions to the respondents: "What was the role of the main contractor [client] during the design phase? To what extent did the contractor commit resources to developing their service and technical offer? How did you involve other businesses at the project definition phase? How did you work with the main contractor to ensure a successful development of the project?" Additionally, to capture the temporal nature of value cocreation, the respondents were requested to explain how different stages of the projects were managed in relation to other stages (e.g., project definition, tender, feasibility, design, procurement, and construction). For example, we asked: "How did you make sure that the contractor addressed your project requirements during the project execution phase? How did you balance the multiple project success factors, such as time and cost, and the post-completion measures? How well did the main contractor manage the transition from the business development stage prequalification to the bid stage, then to starting on-site? How did you manage the transition from the bid stage to the execution phase?"

Specifically, in order to decode why respondents recounted what happened in a particular way, the interview comprised a set of simple follow-up questions whereby any supposedly simple response to the main interview questions was pursued by the interviewers by asking another question about the response. In particular, the background knowledge of the firm and the projects that had been accumulated earlier in the interview allowed the formulation of more appropriate and creative questions regarding the response. 


\subsection{Data analysis}

Data analysis took an interpretative approach, respecting the information provided and emanating context (Denzin, 2002). Respecting key actors' perceptions enriched understanding of attitudes, processes, and behavior, yielding meaning to generate patterns of events and draw attention to outcomes of significance (Smyth \& Morris, 2007).

The data collected were recorded, transcribed, and coded in qualitative data analysis software. The data analysis commenced by preparing case study narrative reports for each case company. Coding, as a crucial aspect of data analysis, was performed following a two-step process, as suggested by Glaser (1978) and Charmaz (2011). We began with a line-by-line review of individual case reports to identify the multiple aspects and dynamics at play in multiplex value cocreation that were manifested within the case data. In particular, we assigned a descriptive label (code) to the segments of text in which the concept was present to cluster the data units into common themes. In order to ensure that the text segments that were assigned to each code reflected the same aspect, we constantly compared the text segments assigned to the same code (Glaser \& Strauss, 1967). We continued the process until no new codes emerged (Eisenhardt, 1989). Ultimately, we identified six themes, including the key multiplex value cocreation processes and the mechanisms that underpin their development. We then conducted the process of generating higher-order codes (Strauss \& Corbin, 1990) to conceptualize how the substantive themes were related to each other. In particular, we related the initial codes together and organized them around the three broad categories of resources integration processes (institutional work and resource reconfiguration), resources integration drivers (motives and conflicts) and interaction mechanisms (basis of interactions and span of interactions) as the key components of multiplex value cocreation. These are defined, elaborated, and supported with 
illustrative examples from the case studies in the Findings section.

The coding process was performed by the authors. Additionally, in order to further validate the process, an independent coder was given the analysis and asked to assign sections of the text to the codes that were identified. We verified the extent to which the second coder had allocated the same text segments to the initial codes as the first coders. This then created a basis for the further development of the codes into a robust set of categories.

\section{Findings}

This section outlines and discusses the key observations that emerged from the case study analysis. An overarching observation that arose from the case studies suggested that in value cocreation, actors put in place a set of processes and mechanisms in order to manage the interdependencies existing between/among value cocreation activities in the past, present and future. In particular, our findings revealed that actors engage in two interrelated resource integration processes — institutional work and resource reconfiguration — driven by motives and conflicts. Our results further showed the basis and span of interactions between/among actors through which the two processes are facilitated (Figure 2).

\section{INSERT FIGURE 2 ABOUT HERE}

\subsection{Resource integration processes}

\subsubsection{Institutional work}

Our findings demonstrated that, in addressing a particular problem or responding to a need, actors, from the inception of value cocreation, engage in the process of identifying resources that have to be integrated in the future. Over time, the actors gradually establish a shared intention of 
the resources that are to be integrated. This will then form a basis for generating institutions through which the resource integrating actors exchange services in the emergent ecosystem. This process has been investigated in the literature through the concept of institutional work as the actors' purposive and collective efforts to create, maintain, and break institutions (KoskelaHuotari, Edvardsson, Jonas, Sörhammar, \& Witell, 2016). The institutions so formed define, guide, and limit the current actions that may impact future service exchanges or require resources that have been created in the past. For instance, in Case I, across projects, the feasibility study, basic design, and contract advice appeared to enable the firm to produce tender bid documents (an initial form of institution) which then allowed for identifying and selecting the potential contractors with whom the project contract (an established form of institution) was finalized. To ensure the mechanical reliability of the infrastructure in future, the contract of a rail infrastructure project, for example, defined the specifications of the construction materials to be used. Furthermore, the contract specified the preferred technologies that were utilized in previous projects as a means to define the construction process.

Institutions became source of conflict and, to resolve these conflicts, actors appeared to establish alternative sets of institutions that cover the deficiencies that exist in single-form institutions. In particular, in our cases, we found that the established institutions may be complemented by other formal and informal institutions or the institutional arrangements of the service ecosystem. One salient example is a megaproject in Case IV, where a combination of outcome-based (e.g., risks) and resource-based (e.g., fixed assets and human capital) criteria were featured in the contract to ensure flexibility in addressing the contextual dynamics. In order to facilitate conflict resolution, the contract (i.e., a formal institution) was further complemented with the informal institution of mutual trust (fostered as a result of a number of informal social 
activities in which the senior management of both parties were engaged). Another example observed in our four cases was the improved safety culture that had been shaped by industry actors over time (i.e., an institutional arrangement). The established safety culture appeared to resolve a number of safety-related issues that were not predicted in the contract.

\subsubsection{Resource reconfiguration}

Our analysis of cases suggested that actors do not often possess the resources identified in the established institutions or, owing to contextual dynamics or the deficiencies of institutions, may even require resources beyond those identified. Therefore, in order to align their resources with the requirements of different time contexts, actors must create new resource combinations or reconfigure their existing resources (i.e., resource reconfiguration). In particular, actors appeared to reconfigure their resources through various innovation mechanisms, such as value engineering (e.g., as observed in Case IV) and supply chain re-design (e.g., as observed in Case I). The reconfiguration of resources often involves multiple actors, as meeting the requirements of the present and future or indeed the limitations of the past concerns resources that are owned or controlled by multiple parties. Case I, again, offers a relevant example, where the relatively low budget set for a project by the government was in conflict with the deliverables for which an allocation of high financial resources was required. Consequently, in order to meet the present budget limitations and the future objectives of the project at the same time, the firm worked with its main contractor to reconfigure the underlying supply chain. A Case I infrastructure projects director stated:

The interface is firstly with the government before securing funding for procurement. The core element is the financial aspects and the configuration of the supply chain. The supply chain is seen as absolutely crucial to save costs, how they can help each other [between 
Case I and their suppliers] to reduce cost. Innovativeness is built around the notion and calculations toward risks, costs, and materials.

In another example, Case III appeared to share its construction capacity with other contractors through partnership arrangements (consortium agreement) to propose an offer that fulfils the requirements identified in the bid documents.

Our results also revealed instances where the reconfiguration of resources did not smoothly take place, owing to the actors' limited ability to integrate, gain, or release resources. For instance, the process of creating new resource combinations to respond to the emerging project requirements appeared to be impeded, such that Case II did not have the capacity to embrace the new technology that became required because of the adoption of a higher level of building information modeling.

\subsection{Resource integration drivers}

\subsubsection{Motives}

Resource integration motives are defined as "a set of energetic forces originating both within the actor and from the (social) context, to initiate resource integration and determine its direction, intensity, and persistence" (Findsrud, Tronvoll, \& Edvardsson, 2018, p. 13). Firstly, our case studies suggested that actors invest in resources and in relationships with other actors to establish institutions that could serve their future interests. For instance, Case II invested in resources to support the early contractor involvement initiative of one of its major clients. In particular, assisting the client in setting up the contract (an established form of institution) at an early stage provided the firm with more flexibility and feasibility in terms of modifying the project 
requirements, rather than during the later implementation phases. According to a project manager from Case II:

Early contractor involvement is critical from the project management perspective for building relationships. For [company $x$ ], this needs to be [a project management excellence framework] stage 4, as stage 5, post-tender, is too late to have much of an effect, especially on added value, value for money and via value engineering. Cost reduction is to the fore of thinking, more so than added value. Stage 4 early contractor involvement is vital for influencing design, as much outline design does not heed principles of how it can be constructed on-site, and early contractor involvement helps to tweak the process so that detailed design is more aligned with actual construction planning and methods. Behaviors are key to making this a success. Good front-end stuff too!

The analysis of our cases further suggested that the institutional work could be negatively influenced by resource integration motives. For instance, in one of the megaprojects in Case I, the main contractor appeared to overpromise at the prequalification and bid stages in order to win the project. According to the Case I asset management director:

Sometimes, suppliers are too willing to adapt to the client's approach. This is dangerous, sometimes, clients expect suppliers to be a bit more 'hard' and say the truth. However, suppliers ... are rarely willing to say when they cannot do something, so as to not overpromise. Suppliers should be brave to walk away from a project.

Secondly, we have determined that resource integration motives define the degree to which actors commit to resource reconfiguration activities. For instance, Case IV ranks its clients based on their attractiveness (e.g., client's reputation, client's project budget, mutual trust, and mutual 
understanding) and prioritizes the high-ranked clients when a reconfiguration of resources is required. Conversely, a high demand for infrastructure facilities and the lack of supply market capacity appeared to make the main contractors of Case I less motivated to invest in innovation and commit resources to developing new technologies to enhance their service offerings.

\subsubsection{Conflicts}

Our results revealed that multiplex resource integration processes are driven by conflicts arising from the temporal nature of value cocreation. Firstly, the findings showed that actors engage in institutional work to avoid potential conflicts that may result from the use of inappropriate resources such as equipment (Case I), construction works (Cases II and IV) and mechanical and electrical works (Case III) in the execution of the projects. Secondly, actors engage in resource reconfiguration processes to address the conflicts resulting from a lack of resources in the present

(e.g., limited construction capacity as in Case III) or in the future (e.g., limited access to financial resources, Case IV) and potential changes to resources (e.g., project team re-allocation, Case II).

Our findings also demonstrated that the outcomes of institutional work and resource reconfiguration processes may themselves become a source of conflict. First, our cases revealed that while institutions are generated based on the desired future experiences of the beneficiaries, these institutions may not be accurate in predicting the future events and associated outcomes or in evaluating available resources, and thus they can become a source of conflict in the later stages of value cocreation. For instance, a conflict arose between Case I and a main contractor, where, in order to achieve the main objective of the project, the firm was demanding that the contractor allocate resources that were not set in the contract (e.g., new equipment specifications). Similarly, in Case III, a conflict occurred between the firm and a major client, whereby the set contract between the two parties did not accurately identify the exact resources, 
processes, and outcomes required to be integrated in the implementation phase (e.g., mechanical and electrical procedures).

Second, in addressing the emerging requirements of a different time context, the newly created resource reconfigurations may cause conflict in value cocreation occurring in other service exchanges. Cases II and IV offer relevant examples, where a newly embarked major project required the contractors to move their experienced senior employees from an ongoing project approaching its final stages to work on the new undertaking. This, however, resulted in lost knowledge and impeded project progress, and thus precluded a successful delivery. Similarly, the change in supply chain strategy of one of Case I's main contractors from a costbased strategy to a risk-oriented supply chain management approach appeared to prevent Case I from meeting its limited budget targets too.

\subsection{Interaction mechanisms}

\subsubsection{Basis of interaction}

Our results revealed that actors managed the interdependencies of value cocreation in the past, present, and future by frequently interacting with other actors. In particular, the analysis of our cases suggested that actors interact with each other predominantly to: (1) communicate about their resources, (2) reach a mutual understanding of the established institutions, (3) identify institutional deficiencies and contextual changes, and (4) reconfigure resources.

Firstly, actors communicate information about their existing resources in order to create shared intentions over future resource integrations. For instance, Case III appeared to continually present and promote its available resources and previous project achievements to the clients to encourage them to develop project requirements that are well-matched with the contractor's 
capabilities. Secondly, our results demonstrated that actors communicate institution-related information to clarify promises, agreements, rules, and norms that were set in the past. For example, in all our cases, the actors appeared to revisit, via meetings, correspondence, and informal interactions, the contracts and agreements formed in the past to clarify how the projects had to proceed. Thirdly, we observed that actors interact with each other to identify the deficiencies of institutions and the contextual change-related issues as well as to discuss the potential resource reconfiguration that may be required. For example, Case III and their clients regularly monitored project progress and the key performance indicators through meetings, visitations, and audits to decide upon new investments, activities, and technologies required for the successful completion of the project. Finally, findings indicated that actors who have not previously accumulated the resources (e.g., social capital, expertise, or assets) necessary for forming an institution tend to engage in alliances for customized design, tailored solutions, joint problem-solving (as demonstrated in all our cases), outcome specifications (Cases II-IV), and project requirements (Case I). Case I serves as a case in point, whereby the firm was involved in a megaproject to deliver a new type of service outside its core capabilities. Although the firm had sought to increase its capabilities in this area over the past few years, they still had difficulties in identifying potential project requirements. The firm therefore arranged a collaboration with one of the main contractors in the industry to identify and finalize these requirements, which was then used as a basis for producing the bid tender documents and final contract.

\subsubsection{Span of interaction}

Interactions appeared to take place through interrelated joint processes that connect individual actors from varying strategic and operational levels. For instance, in Case I, while the project directors' regular meetings brought the client and contractor together to resolve major issues 
such as contractual changes, the day-to-day problems informed by the outcomes of the directors' meetings were dealt with through on-site informal interactions between/among the operational staff.

These interactions also spread across different parts of each actor's organization and to other actors within the broader service ecosystem with whom these organizations are connected, and continue until a shared intention is arrived at. For instance, a new idea (the adoption of a new construction technology) presented by Case II to a group of experts from a client organization was communicated and consulted with a network of the client's internal and external partners until an agreement was reached.

Our findings further provided evidence that actors engage in a number of practices, such as involving project managers during the early stages of proposal preparation (Cases III and IV), collocating a group of people from the contractor and client teams (Case I), implementing key account management (Case II), and creating cross-functional roles (Case III) to ensure an uninterrupted chain of interactions. For instance, the chief executive of Case III effectively described the formation of the cross-functional role as follows:

Operational divisional managers run activities, transitioning from business development to bidding to execution. Other companies have a cut-off between business development and project management. This is echoed at the board level through board members having responsibility for marketing, for operations and so on.

\section{Discussion and conclusions}

Our study introduced and investigated the notion of multiplex value cocreation. In particular, our work sought to unpack the processes and mechanisms through which actors manage the 
interdependencies between/among value cocreation of the past, present, and future. Our findings uncovered how actors manage the temporal nature of value cocreation through the two resource integration processes of institutional work and resource reconfiguration that are driven by motives and conflicts and facilitated by interaction mechanisms.

Firstly, actors engage in institutional work to ensure the appropriate integration of resources in future. Koskela-Huotari et al. (2016) have recently shown how institutions are changed through institutional work (e.g., through a redefinition of the roles of actors) to enable service innovation. Taillard, Peters, Pels, and Mele (2016) further explained the emergence of institutions that result from actors' engagement with multi-level institutional work such as negotiation, role definitions, and creation of shared intention. Our study clarifies the role of institutional work in addressing the temporal nature of value cocreation and thus contributes to the current literature (e.g., Koskela-Huotari et al., 2016; Taillard et al., 2016) by illustrating that actors utilize existing institutional arrangements or may even form alternative institutions to address the deficiencies that exist in the original institutions established.

Secondly, actors create new resource combinations or reconfigure their existing resources to adapt to the requirements of different time contexts that were not accurately predicted or that simply evolved based on contextual discontinuities. The reconfiguration of resources is initiated by single or multiple actors, and the actors' ability to continually create, extend, and modify their resource base (i.e., reflected in the literature as dynamic capabilities; Helfat et al., 2007; Teece, Pisano, \& Shuen, 1997) and their behaviors towards the reconfiguration activities determine the efficiency and effectiveness of the underlying endeavors. Consistently, Siltaloppi and Vargo (2014) have argued that the resources that actors proposed for integration (i.e., value proposition) can be reproduced locally within resource integration to adapt to the contextual and local actors' 
requirements. We extend this argument by showing that the value propositions are reconfigured even before they are locally integrated to shape institutions. This may result in the emergence of resources with completely new properties (i.e., heteropathic resource integration; Peters, 2016).

Thirdly, our study shows that institutional work and resource reconfiguration are interrelated. Actors engage with resource reconfiguration to meet the objectives of institutional work and they put in place alternative institutions to facilitate resource reconfiguration in future value cocreation. Furthermore, these interrelated processes are driven by actors' motives and conflicts, while their outcomes may also be a source of conflict. Actors' motives have recently captured the attention of value cocreation scholars, whereby those motives are conceptualized as the determinant(s) of the direction, intensity, and persistence of resource integration (Findsurd et al., 2018). Our findings contribute to the better understanding of value cocreation motives by identifying instances in which actors overpromise their value proposition to secure a contract. We can therefore propose openness as an additional influence of motives on resource integration processes. Our results also identified conflicts as a trigger of multiplex value cocreation processes, supporting previous literature on conflicts (Mele, 2011) and further advancing the literature by identifying the outcomes of institutional work and resource reconfiguration themselves as sources of conflicts.

Lastly, we identified interaction mechanisms between/among actors as a crucial element in facilitating multiplex value cocreation processes. Consistent with the existing literature (e.g., Breidbach \& Brodie, 2017; Storbacka et al., 2016), we have identified a set of interaction mechanisms such as meetings, reports, contracts, and project co-location that facilitate institutional work and resource reconfiguration. Our work contributes to this line of research by identifying the basis and the span of interactions in multiplex value cocreation. Specifically, we 
illustrated that actors put in place mechanisms such as early contractor involvement and crossfunctional teams in order to reduce the complexity of interactions over time and within different layers of a service ecosystem.

Therefore, we offer the following proposition:

Proposition 1: Multiplex value cocreation involves institutional work and resource reconfiguration that are: (a) reciprocally interrelated, (b) driven by actor motives and conflicts, and (c) facilitated by interaction mechanisms

Herein, we have investigated the multiplex value cocreation processes and mechanisms in unique service exchanges where these are explicitly practiced by actors. We suggest that any routine service exchange has also been initiated as a pure project with a unique goal in the first instance. However, because these are repeated many times, the uncertainty around resource integration is reduced and may take the form of a routine service. For instance, human flight was pioneered through projects in the late $18^{\text {th }}$ and early $19^{\text {th }}$ centuries, whereas it is now a routine service provided by airlines. In fact, a non-project service is a special form of a project where its objective is not (relatively) unique anymore. Therefore, we suggest that multiplex value cocreation also exists in routine service exchanges. However, they might not be repeatedly practiced by the actors and hence might not be visible. For example, in the case of a customer dining in a restaurant, repeated interdependencies are managed through existing institutions, such as social norms (Akaka et al., 2015) or other forms of social forces (Edvardsson, Tronvoll, \& Gruber, 2011). In fact, those social norms had once emerged as a result of actors' institutional work that is not explicitly done in today's dinning practices (i.e., there may still be implicit institutional work reshaping dinning practices). Furthermore, within routine service exchanges, actors may engage in multiplex value cocreation across service exchanges instead of a unique 
service exchange. For example, a firm may become aware of a customer's requirements in one of their service exchanges and reconfigure its resources to exchange service with other customers. Therefore, we propose:

Proposition 2: The repeated nature of routine service exchanges may mask some of the multiplex value cocreation processes and mechanisms where the emerged institutions and resources and similar previous service exchanges are utilized in managing the temporal nature of value cocreation.

Our study, in general, contributes to the existing literature highlighting the temporal nature of value cocreation (e.g., Chandler \& Lusch, 2015; Storbacka et al., 2016) by explaining how the interdependencies of value cocreation in the past, present, and future are managed. Although the temporal nature of value cocreation has recently been empirically examined with a focus on its dynamic and evolving nature (e.g., Akaka et al., 2015), the literature has not acknowledged the engagement of actors in multiplex value cocreation. By distinguishing between multiplex and core value cocreation processes and mechanisms, we managed to shed light on the presence of a number of the core components of value cocreation, including institutional work, resource reconfiguration, interaction mechanisms, conflicts, and motives. 


\section{References}

Aarikka-Stenroos, L., \& Jaakkola, E. (2012). Value co-creation in knowledge intensive business services: A dyadic perspective on the joint problem solving process. Industrial Marketing Management, 41(1), 15-26.

Akaka, M.A., Vargo, S.L., \& Lusch, R.F. (2013). The complexity of context: A service ecosystems approach for international marketing. Journal of International Marketing, 21(4), 120.

Akaka, M.A., Vargo, S.L., \& Schau, H.J. (2015). The context of experience. Journal of Service Management, 26(2), 206-223.

Ballantyne, D., Frow, P., Varey, R.J., \& Payne, A. (2011). Value propositions as communication practice: Taking a wider view. Industrial Marketing Management, 40(2), 202-210.

Blindenbach-Driessen, F., \& van den Ende, J. (2006). Innovation in project-based firms: The context dependency of success factors. Research Policy, 35(40), 545-561.

Breidbach, C.F., \& Brodie, R.J. (2017). Engagement platforms in the sharing economy: Conceptual foundations and research directions. Journal of Service Theory and Practice, 27(4), $761-777$.

Chandler, J.D., \& Vargo, S.L. (2011). Contextualization and value-in-context: How context frames exchange. Marketing Theory, 11(1), 35-49.

Chandler, J.D., \& Lusch, R.F. (2015). Service systems: A broadened framework and research agenda on value propositions, engagement, and service experience. Journal of Service Research, $18(1), 6-22$. 
Christopher, M. (2005), Logistics and Supply Chain Management: Creating Value-Adding Networks ( $3^{\text {rd }}$ ed.). UK: Pearson Education Limited.

Charmaz, K. (2011). Grounded theory methods in social justice research. In N.K. Denizen, \& Y.S. Lincoln (Eds.), The Sage Handbook of Qualitative Research, (pp. 359-380), Thousand Oaks, CA: SAGE.

Crespin-Mazet, F., \& Ghauri, P. (2007). Co-development as a marketing strategy in the construction industry. Industrial Marketing Management, 36(2), 158-172.

Denzin, N.K. (2002). The Interpretive Process. In: A.M. Huberman, \& M.B. Miles (Eds.), The Qualitative Researcher's Companion, (pp. 349-366). Thousand Oaks, CA: Sage Publications.

Dyer JR, W.G., \& Wilkins, A.L. (1991). Better stories, not better constructs, to generate better theory: A rejoinder to Eisenhardt. Academy of Management Review, 16(3), 613-619.

Edvardsson, B., Tronvoll, B., \& Gruber, T. (2011). Expanding understanding of service exchange and value co-creation: A social construction approach. Journal of the Academy of Marketing Science, 39(2), 327-339.

Eisenhardt, K.M. (1989). Agency theory: An assessment and review. The Academy of Management Review, 14(1), 57-74.

Eisenhardt, K.M., \& Graebner, M.E. (2007). Theory building from cases: Opportunities and challenges. Academy of Management Journal, 50(1), 25-32.

Findsrud, R., Tronvoll, B., \& Edvardsson, B. (2018). Motivation: The missing driver for theorizing about resource integration. Marketing Theory, 1-13. https://doi.org/10.1177/1470593118764590. 
Glaser, B.G. (1978). Theoretical Sensitivity: Advances in the Methodology of Grounded Theory. Mill Valley, CA: Sociology Press.

Glaser, B.G., \& Strauss, A.L. (1967). The Discovery of Grounded Theory: Strategies for Qualitative Research, Chicago: Aldine Publishing Company.

Grönroos, C. (2011). A service perspective on business relationships: The value creation, interaction and marketing interface. Industrial Marketing Management, 40(2), 240-247.

Grönroos, C., \& Gummerus, J. (2014). The service revolution and its marketing implications: Service logic vs service-dominant logic. Managing Service Quality, 24(3), 206-229.

Grönroos, C., \& Voima, P. (2013). Critical service logic: Making sense of value creation and cocreation. Journal of the Academy of Marketing Science, 41(2), 133-150.

Gummesson, E., \& Mele, C. (2010). Marketing as value co-creation through network interaction and resource integration. Journal of Business Market Management, 4(4), 181-198.

Gummerus, J. (2013). Value creation processes and value outcomes in marketing theory: Strangers or siblings? Marketing Theory, 13(1), 19-46.

Helfat, C.E., Finkelstein, S., Mitchell, W., Peteraf, M.A., Singh, H., Teece, D.J., \& Winter, S. (2007). Dynamic capabilities: Understanding strategic change in organizations. Malden, MA: Blackwell Publishing.

Helkkula, A., Kelleher, C., \& Pihlstrom, M. (2012). Characterizing value as an experience: Implications for service researchers and managers. Journal of Service Research, 15(1), 59-75. Hsu, J.S., Hung, Y.W., Chen, Y.H., \& Huang, H.H. (2013). Antecedents and consequences of user coproduction in information system development projects. Project Management Journal, $44(2), 67-87$. 
Koskela-Huotari, K., Edvardsson, B., Jonas, J.M., Sörhammar, D., \& Witell, L. (2016). Innovation in service ecosystems - Breaking, making, and maintaining institutionalized rules of resource integration. Journal of Business Research, 69(8), 2964-2971.

Liu, A.M.M., Fellows, R., \& Chan, I.Y.S. (2014). Fostering value co-creation in construction: A case study of an airport project in India. International Journal of Architecture, Engineering and Construction, 3(2), 120-130.

McColl-Kennedy, J.R., Vargo, S.L., Dagger, T.S., Sweeney, J.C., \& van Kasteren, Y. (2012). Healthcare customer value cocreation practice styles. Journal of Service Research, 15(4), 370389.

McColl-Kennedy, J.R., Hogan, S.J., Witell, L., \& Snyder, H. (2017). Cocreative customer practices: Effects of health care customer value cocreation practices on well-being. Journal of Business Research, 70, 55-66.

Mele, C. (2011). Conflicts and value co-creation in project networks. Industrial Marketing Management, 40(8), 1377-1385.

Meynhardt, T., Chandler, J.D., \& Strathoff, P. (2016). Systematic principles of value co-creation: Synergetics of value and service ecosystems. Journal of Business Research, 69(8), 2981-2989.

Morris, P.W.G. (2002). Science, objective knowledge and the theory of project management. Proceedings of the ICE - Civil Engineering, 150(2), 82-90.

Morris, P.W.G. (2013). Reconstructing project management reprised: A knowledge perspective. Project Management Journal, 44(5), 6-23.

Papke-Shields, K.E., Beise, C., \& Quan, J. (2010). Do project managers practice what they preach, and does it matter to project success? International Journal of Project Management, 
$28(7), 650-662$.

Patton, M.Q. (2015). Qualitative research and evaluation methods. (4 ${ }^{\text {th }}$ ed.). Thousand Oaks, CA: Sage.

Pera, R., Occhiocupo, N., \& Clarke, J. (2016). Motives and resources for value co-creation in a multi-stakeholder ecosystem: A managerial perspective. Journal of Business Research, 69(10), $4033-4041$.

Peters, L.D. (2016). Heteropathic versus homopathic resource integration and value co-creation in service ecosystems. Journal of Business Research, 69(8), 2999-3007.

Porter, M. (1985), Competitive Advantage: Creating and Sustaining Superior Performance, New York: Free Press.

Razmdoost, K., \& Mills, G.R.W. (2016). Towards a service-led relationship in project-based firms. Construction Management and Economics, 34 (4-6), 317-334.

Siltaloppi, J., \& Vargo, S.L. (2014, January). Reconciling resource integration and value propositions - The dynamics of value co-creation. 47th Hawaii International Conference on System Science, Waikoloa, HI, pp. 1278-1284, DOI 10.1109/HICSS.2014.165.

Smyth, H.J., \& Morris, P.W.G. (2007). An epistemological evaluation of research into projects and their management: Methodological issues. International Journal of Project Management, $25(4), 423-436$.

Smyth, H., Lecoeuvre, L., \& Vaesken, P. (2018). Co-creation of value and the project context: Towards application on the case of Hinkley Point C nuclear power station. International Journal of Project Management, 36(1), 170-183.

Storbacka, K., Brodie, R.J., Böhmann, T., Maglio, P.P., \& Nenonen, S. (2016). Actor 
engagement as a microfoundation for value co-creation. Journal of Business Research, 69(8), $3008-3017$.

Strauss, A., \& Corbin, J. (1990). Basics of qualitative research: Grounded theory procedures and techniques. Newbury Park, CA: Sage.

Taillard, M., Peters, L.D., Pels, J., \& Mele, C. (2016). The role of shared intentions in the emergence of service ecosystems. Journal of Business Research, 69(8), 2972-2980.

Teece, D.J., Pisano G., \& Shuen, A. (1997). Dynamic capabilities and strategic management. Strategic Management Journal, 18(7), 509-533.

Tommasetti, A., Troisi, O., \& Vesci, M. (2017). Measuring customer value co-creation behavior: Developing a conceptual model based on service-dominant logic. Journal of Service Theory and Practice, 27(5), 930-950.

Truong, Y., Simmons, G., \& Palmer, M. (2012). Reciprocal value propositions in practice: Constraints in digital markets. Industrial Marketing Management, 41, 197-206.

Turner, J.R., \& Müller, R. (2003). On the nature of the project as a temporary organization. International Journal of Project Management, 21(1), 1-8.

Vargo, S.L., \& Lusch, R.F. (2004). Evolving to a new dominant logic for marketing. Journal of Marketing, 68(1), 1-17.

Vargo, S.L., \& Lusch, R.F. (2006). Service-dominant logic: What it is? What it is not? and What it might be? In R.F Lusch, \& S.L. Vargo. (Eds.), The service dominant logic of marketing (pp. 43-56). New York: M.E. Sharpe.

Vargo, S.L., \& Lusch, R.F. (2008). Service-dominant logic: Continuing the evolution, Journal of Academy of Marketing Science, 36(1), 1-10. 
Vargo, S.L., \& Lusch, R.F. (2016), Institutions and axioms: An extension and update of servicedominant logic, Journal of Academy of Marketing Science, 44(1), 5-23.

Ward, S.C., \& and Chapman, C.B. (1995). Risk-management perspective on the project lifecycle. International Journal of Project Management, 13(3), 145-149.

Warde, A. (2005). Consumption and theories of practice. Journal of Consumer Culture, 5(2), $131-153$

Watson, E., \& Shove, E. (2008). Product, competence, and project and practice: DIY and the dynamics of craft consumption. Journal of Consumer Culture, 8(1), 69-89.

Yin, R.K. (2013). Case study research: Design and methods. (5 ${ }^{\text {th }}$ ed.). Thousand Oaks, CA: Sage publications. 


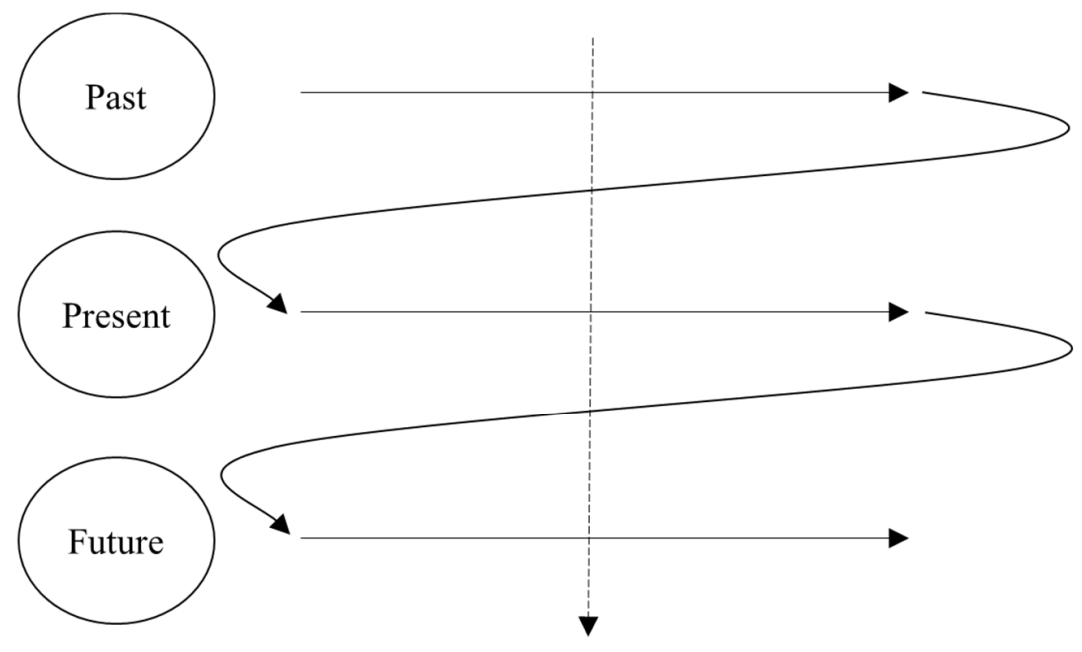

- Value cocreation processes and mechanisms

- Multiplex value cocreation

Emergence of resources and institutions

Figure 1, Conceptual Framework of Value Cocreation 


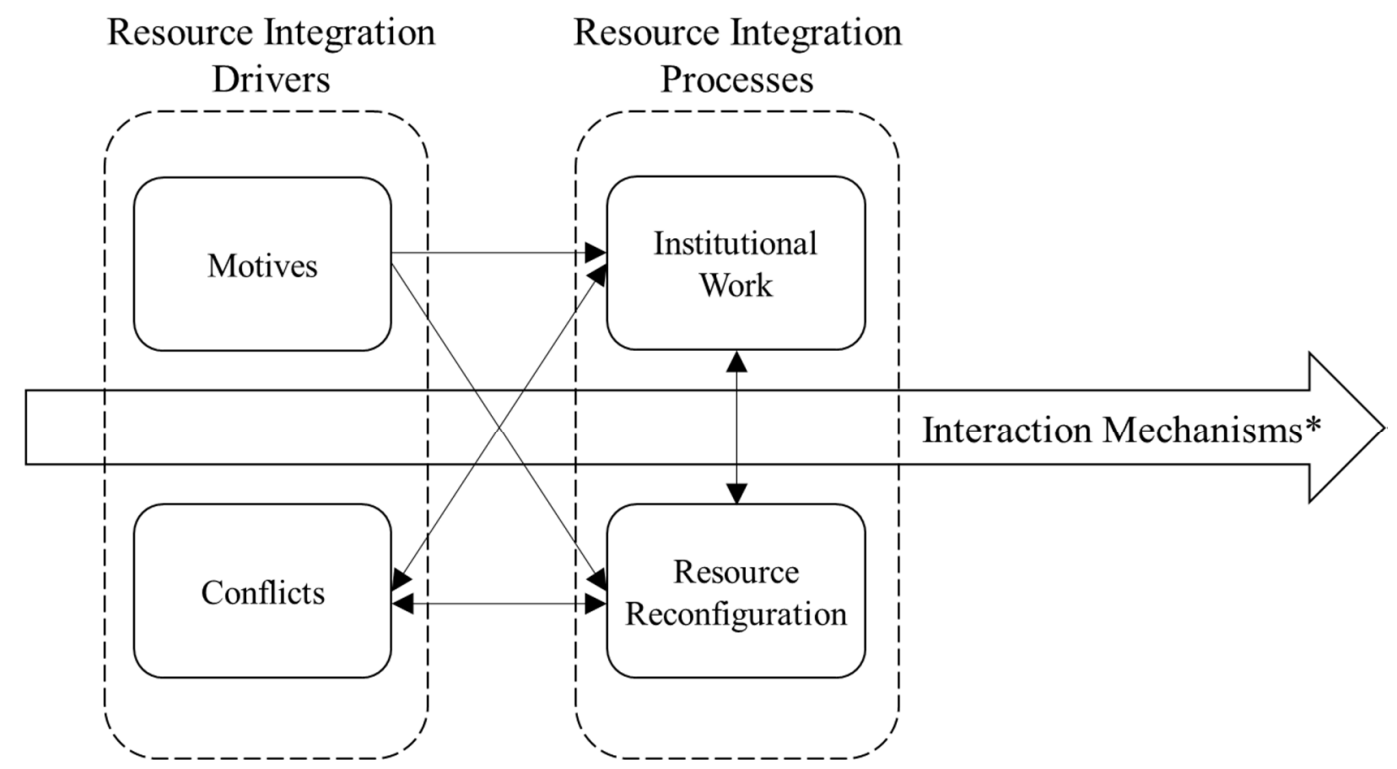

* Including basis and span of interactions

Figure 2, Multiplex Value Cocreation 
Table 1. An Overview of the Cases and Data Sources

\begin{tabular}{|c|c|c|c|c|c|}
\hline Case & Role & $\begin{array}{l}\text { Primary } \\
\text { Activities }\end{array}$ & Types of projects studied & $\begin{array}{l}\text { Issues related to the temporal nature of value } \\
\text { cocreation }\end{array}$ & Interview Respondents \\
\hline I & Client & Rail transport & $\begin{array}{l}\text { - New infrastructure projects: Funding } \\
\text { allocated centrally into programs of } \\
\text { work within which projects are } \\
\text { identified and contracted out to main } \\
\text { contractors } \\
\text { - Renewal projects: Upgrades of } \\
\text { infrastructure, organized as programs } \\
\text { that include a range of projects from } \\
\text { megaproject size, }>\$ 1 \mathrm{bn} \text {, to small } \\
\text { works. }\end{array}$ & $\begin{array}{l}\text { - Ensuring the execution of safe, high-quality, } \\
\text { and innovative construction, mechanical and } \\
\text { electrical work as well as reliable procurement } \\
\text { and installation of equipment and material. } \\
\text { - Building resources and capabilities required for } \\
\text { project definition and execution such as a low- } \\
\text { cost and reliable supply chain and competency in } \\
\text { identifying project requirements. } \\
\text { - Addressing changes over the project lifecycle } \\
\text { such as a strategic shift of a main contractor from } \\
\text { a cost-driven supply chain to a risk-driven } \\
\text { (resilient) supply chain. }\end{array}$ & $\begin{array}{l}\text { - Infrastructure Projects } \\
\text { Director } \\
\text { - Asset Management } \\
\text { Director } \\
\text { - Commercial Director } \\
\text { - Regional Director }\end{array}$ \\
\hline II & Contractor & $\begin{array}{l}\text { Building, civil } \\
\text { engineering and } \\
\text { infrastructure, } \\
\text { and consultancy }\end{array}$ & $\begin{array}{l}\text { Case II undertakes electrical and civil } \\
\text { engineering, and some } \\
\text { construction/building work for } \\
\text { infrastructure clients. They undertake } \\
\text { large complex projects, typically } \\
\text { between } £ 10 \mathrm{~m} \text { and } £ 100 \mathrm{~m} \text {. Many } \\
\text { projects require specialist subcontractors, } \\
\text { and on some projects all work is } \\
\text { subcontracted, with the contractor acting } \\
\text { in the management role of appointing, } \\
\text { integrating the supply chain, and } \\
\text { coordinating work on-site in the systems } \\
\text { coordinator role. It also employs a large } \\
\text { number of temporary agency labor. }\end{array}$ & $\begin{array}{l}\text { - Ensuring the execution of construction works } \\
\text { within the predefined project cost, time and } \\
\text { scope. } \\
\text { - Building resources and capabilities required for } \\
\text { the project execution such as developing } \\
\text { innovative construction technologies and } \\
\text { building technical knowledge. } \\
\text { - Securing project leads through developing } \\
\text { relational capital. } \\
\text { - Managing resources such as project managers } \\
\text { and senior teams across projects. }\end{array}$ & $\begin{array}{l}\text { - Business Development } \\
\text { Director } \\
\text { - } 2 \text { Business Development } \\
\text { Managers } \\
\text { - Head of Procurement } \\
\text { - } 2 \text { Project Managers }\end{array}$ \\
\hline
\end{tabular}




\begin{tabular}{|c|c|c|c|c|c|}
\hline Case & Role & $\begin{array}{l}\text { Primary } \\
\text { Activities }\end{array}$ & Types of projects studied & $\begin{array}{l}\text { Issues related to the temporal nature of value } \\
\text { cocreation }\end{array}$ & Interview Respondents \\
\hline III & Contractor & $\begin{array}{c}\text { Civil } \\
\text { engineering and } \\
\text { infrastructure, } \\
\text { and specialist } \\
\text { subcontracting }\end{array}$ & $\begin{array}{l}\text { Case III conducts complex civil } \\
\text { engineering and construction, typically } \\
\text { multi-million-pound work up to } \\
\text { c.£100m. It has one specialist civil } \\
\text { engineering subcontractor that is in high } \\
\text { demand as an independent subcontractor } \\
\text { and on the main contracts won by this } \\
\text { firm. Case III treats this contractor as an } \\
\text { in-house firm. It also employs direct } \\
\text { labor on-site at an above-average level } \\
\text { for main contractors, some of which } \\
\text { involves a degree of routinized activity. }\end{array}$ & $\begin{array}{l}\text { - Ensuring the execution of civil engineering and } \\
\text { construction works within the predefined project } \\
\text { cost, time and scope. } \\
\text { - Building construction capacity and specific } \\
\text { project expertise (e.g., transportation) required } \\
\text { for potential projects. } \\
\text { - Promoting existing capabilities such as } \\
\text { sustainable construction technologies to the } \\
\text { potential clients. }\end{array}$ & $\begin{array}{l}\text { - } \text { Chief Executive } \\
\text { - } 2 \text { Regional Business } \\
\text { Development Managers } \\
\text { - Senior Business } \\
\text { - } 2 \text { Buelopment Manager } \\
\text { Managers } \\
\text { - Head of Public Relations } \\
\text { and Communications } \\
\text { - } \text { Contracts Manager } \\
\text { - Head of Business } \\
\text { Processes \& Sustainability }\end{array}$ \\
\hline IV & Contractor & $\begin{array}{l}\text { Building, civil } \\
\text { engineering and } \\
\text { infrastructure, } \\
\text { and specialist } \\
\text { subcontracting }\end{array}$ & $\begin{array}{l}\text { Case IV undertakes complex civil } \\
\text { engineering and construction work in the } \\
£ 10 \mathrm{~m}-£ 100 \mathrm{~m} \text { cost range. It has several } \\
\text { specialist subcontractors that are treated } \\
\text { as in-house suppliers, albeit sometimes at } \\
\text { arm's length. This contractor relies } \\
\text { heavily on subcontracting and agency } \\
\text { staff on-site. }\end{array}$ & $\begin{array}{l}\text { - Ensuring the execution of construction works } \\
\text { within the predefined project cost, time and } \\
\text { scope. } \\
\text { - Dealing with project uncertainty and } \\
\text { unpredictability. } \\
\text { - Developing low-cost and efficient construction } \\
\text { technologies required for potential projects. } \\
\text { - Securing project leads through developing } \\
\text { relational capital. } \\
\text { - Managing resources such as project managers } \\
\text { and senior teams across projects. }\end{array}$ & $\begin{array}{l}\text { - } \text { Customer Solutions } \\
\text { Director } \\
\text { - Head of Business } \\
\text { Development } \\
\text { - Sector Business } \\
\text { - Development Manager } \\
\text { - Business Development } \\
\text { - } \text { Coordinator } \\
\text { - } \text { Commercial of Procurement } \\
\text { - Technical Service Director } \\
\text { - } 2 \text { Project Directors }\end{array}$ \\
\hline
\end{tabular}

